\title{
Process Design for Hot Forging of Asymmetric to Symmetric Rib-web Shaped Steel
}

H. Cho, B. Oh, C. Jo, K. Lee

The process design of hot forging, asymmetric to symmetric rib-web shaped steel, which is used for the turnout of express rails has been studied. Owing to the great difference in shape between the initial billet and the final forged product, it is impossible to hot forge the rail in a single stage operation. Therefore, multi stage forging and also die design for each stage are necessary for the production process. The numerical simulation for hot forging of asymmetric shape to symmetric shape was carried out using commercial FEM code, DEFORMT ${ }^{M}-2 D$. Modification of the design and repeated simulation was carried out on the basis of the simulation results. For comparison with the simulation results, a flow analysis experiment using plasticine was also carried out. The results of the flow analysis experiment showed good agreement with those of the simulation.

Keywords: process design, hot forging, asymmetric, symmetric, high speed rail.

\section{Introduction}

The process design for hot forging has been greatly dependent upon the empirical experience of engineers because there are numerous process variables on the basis of constant volume such as prediction of metal flow, yielding condition, heat transfer between dies and forging material, friction behavior, etc. The differences in the personal experience of engineers could lead to empirical errors in real production.

Recently, there have been many reports an effort to save time and cost in die manufacturing through computer aided process design and simulation to reduce process errors [1-7]. Ward [4] analyzed the effect of heat on material and dies during multi stage hot forging of train wheels through the commercial finite element code DEFORM. Qingbin [5] studied the effect of die temperature and forging speed by simulation of thermal behavior during high speed hot forging of AISI 1045 discs. Doege [6] studied closed dies to produce spur gear, helical gear and connecting rods. Choi [7] developed an automatic system that is available to design a blocker to forge rib-web shape products. However, most of the work has concentrated on plane symmetric or axi-symmetric products. Recently, there has been interest in forging asymmetric or axi-asymmetric products, but very few reports have been found on the subject.

Generally, rib-web shaped asymmetric rails for an express train [KS70S] are produced in a specified fixed shape, but the shape transforms to symmetric at the rail turnouts. In the present study, the process design of forging the asymmetric rail to a symmetric rail at the turnouts was carried out by the rigid plastic finite element code DEFORM ${ }^{\mathrm{TM}}-2 \mathrm{D}$ simulation. The process design through computer simulation was also compared with an experimental inspection of the flow behavior with plasticine simulation material.

\section{FEM analysis}

A high speed rail has a rib-web asymmetric [KS70S] to symmetric [KS60KG] shape transition range at the turnouts, as shown in Fig. 1. Owing to the difference in height and shape between the two shapes, it is impossible to forge in a single-stage operation. Therefore, a process design for multi stage forging is needed.

a)

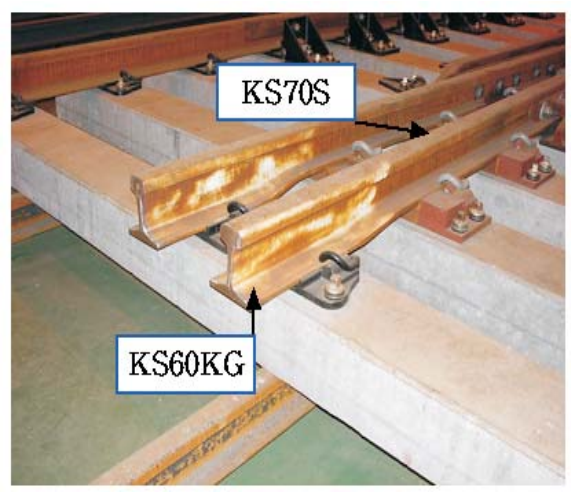

b)

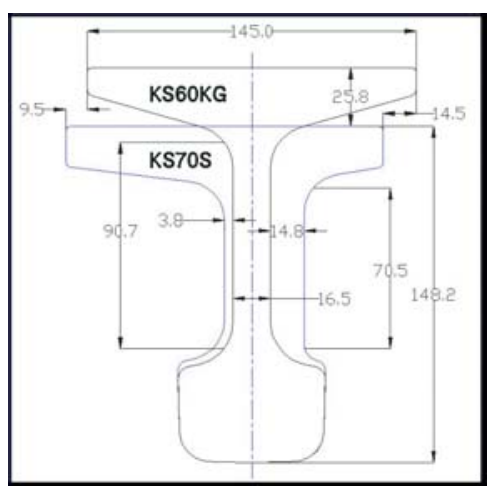

Fig. 1: The shape of transformed parts from KS70S to KS60KG in turnouts: a) photograph of turnouts, b) schematic comparison of the two rail shapes.

Fig. 2 displays the structure of the forging dies the top die on the right and left dies with insert. Because KS70S is eccentric, as shown in Fig. 1b, the height of the left die and the right die was adjusted as shown in Fig. 2 to forge a different amount of deformation on each side. 


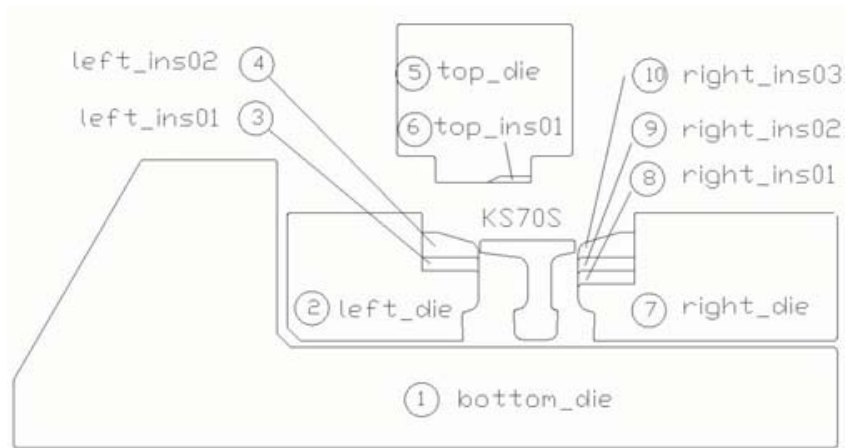

Fig. 2: Schematic illustration of forging dies

For the simulation, the following assumptions for the variables are implied: the dies are rigid bodies, fixed left die, the moving velocity of the right and the upper dies is $2 \mathrm{~mm} / \mathrm{s}$. The boundary conditions are an initial rail temperature of $1050{ }^{\circ} \mathrm{C}$, a preheated die temperature of $100-200^{\circ} \mathrm{C}$, considering heat transfer all the surface and internal body of the dies and insert, friction factor 0.1 between the dies and friction factor 0.3 between rail and dies. The thermal properties of the materials are listed in Table 1.

Table 1: Thermal properties of materials

\begin{tabular}{|c|c|c|}
\hline Material & $\begin{array}{c}\text { Thermal Conductivity } \\
(\mathrm{W} / \mathrm{m} \cdot \mathrm{K})\end{array}$ & $\begin{array}{c}\text { Heat Capacity } \\
(\mathrm{J} / \mathrm{g} \cdot \mathrm{K})\end{array}$ \\
\hline AISI 1055 (rail) & 51.9 & 0.472 \\
\hline AISI H-13 (die) & 28.6 & 0.460 \\
\hline
\end{tabular}

Fig. 3 displays the initiation of folding during subsequent forging processes when there is a fillet angle of $45^{\circ}$ between the side dies and the insert. Designing with an increased fillet angle of $60^{\circ}$ can prevent the folding phenomenon and reduce friction wear due to stress concentration between the die and the insert. Fig. 4 shows the folding initiation at the crossing point during web forming by the upper die. This figure

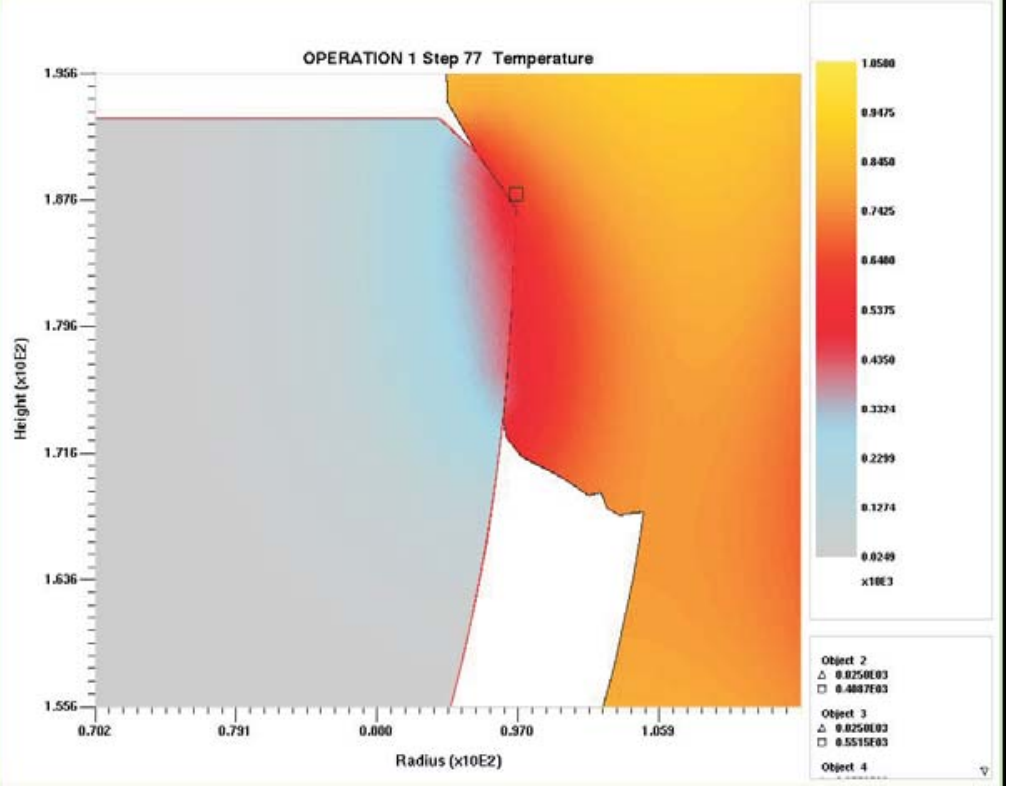

Fig. 3: Folding initiation at a small fillet angle $\left(45^{\circ}\right)$ of moving die and inserts
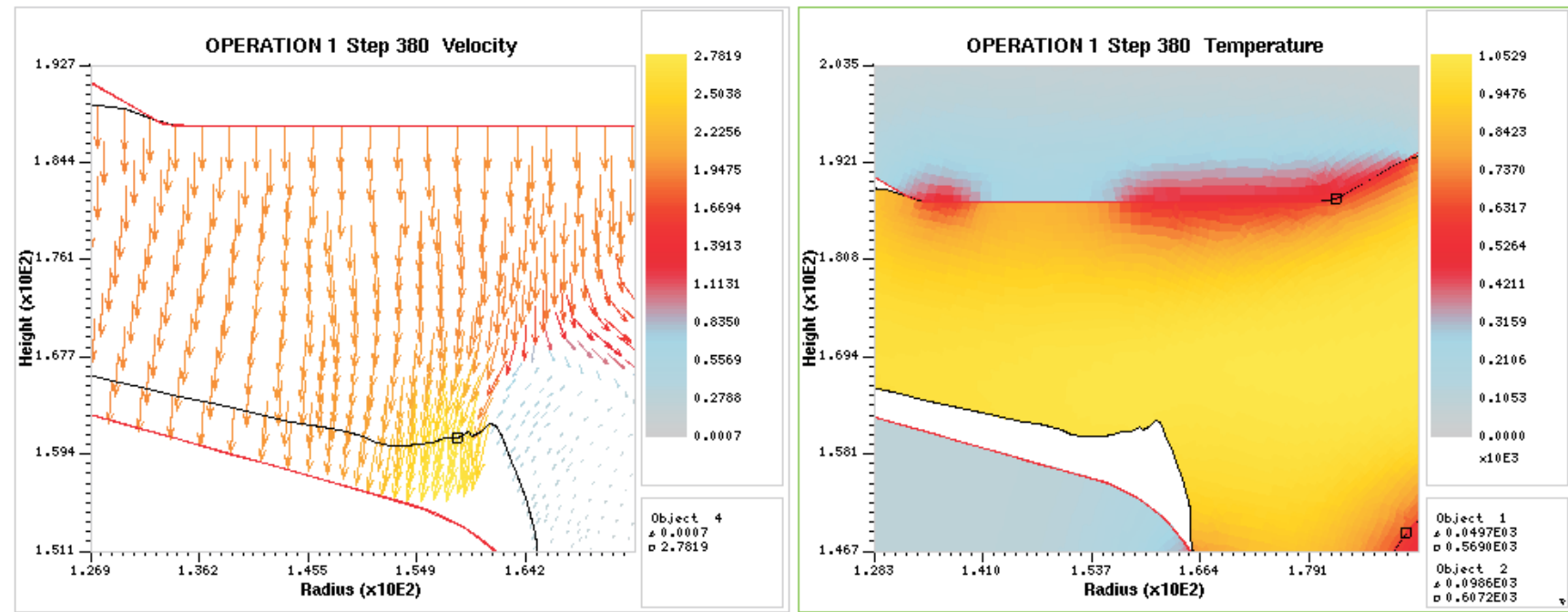

Fig. 4: Folding initiation between rib and web by top die 


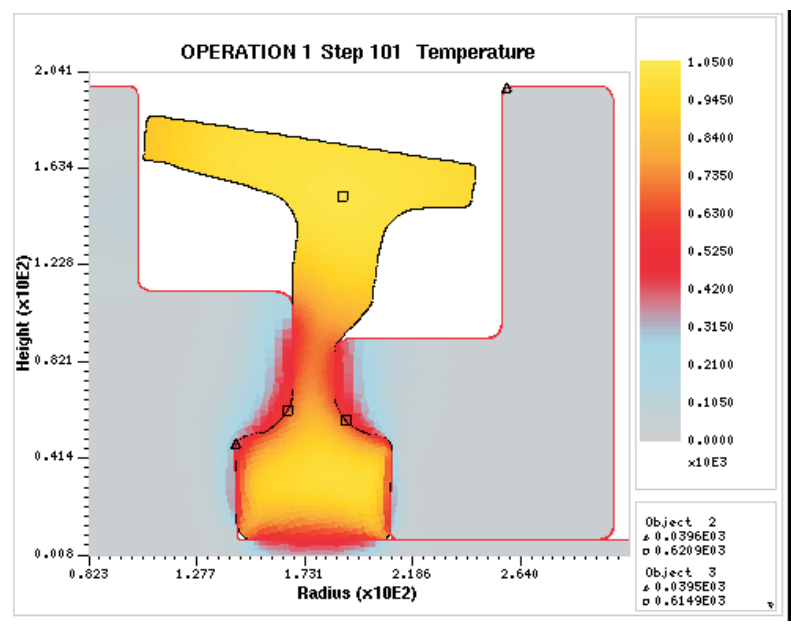

a)

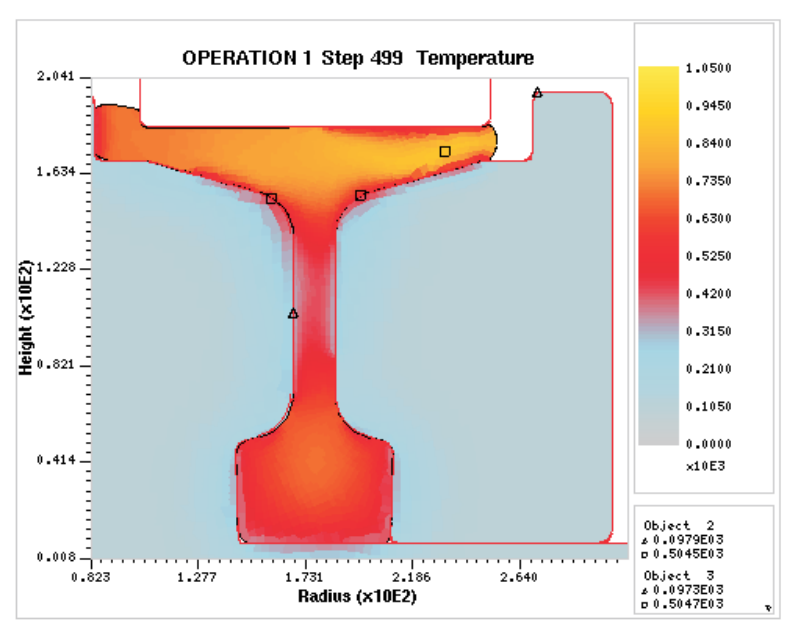

b)

Fig. 5: Simulated forging process (die velocity $2.0 \mathrm{~mm} / \mathrm{s}$, preheating $100{ }^{\circ} \mathrm{C}$ ): a) the end of the 1 st stage, b) the end of the 5 th stage

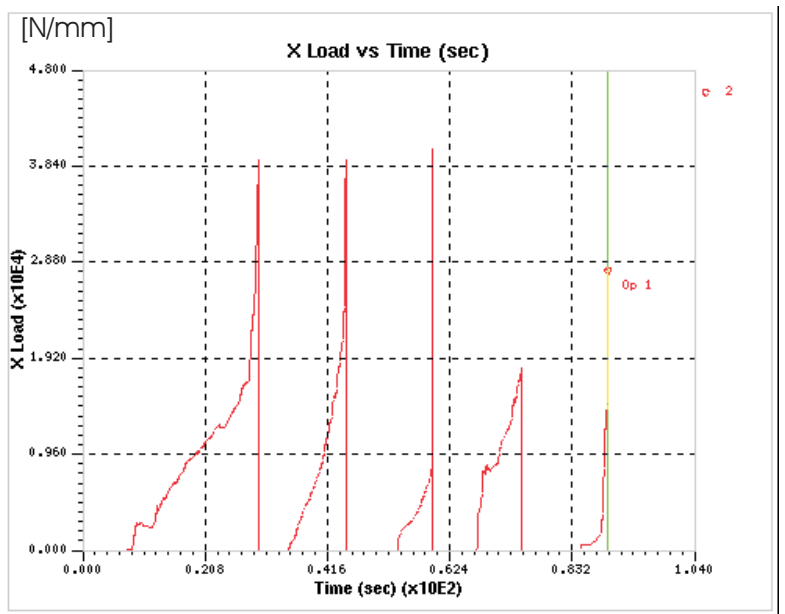

Fig. 6: Impressed load per unit length of the side die

shows that the metal flow and the folding phenomenon are dependent upon the beginning point of the tapered corner in the upper die.

Fig. 5 shows the simulated results when the machining allowance is $0.6 \mathrm{~mm}$ for the whole part. The simulated final shape was within the machining allowance of $0.6 \mathrm{~mm}$, as shown in Fig. 5b. However, the load increased rapidly at the end of the first forging stage, as shown in Fig. 6. The rapid increase in the load is attributed to the increase in the contacting area caused by filling of the internal die cavity with the finished forming of the head of the rail at this stage. Therefore, optimal die design is necessary in order to avoid an increase in the forming load.

Fig. 7 shows the modified forging process of Fig. 5 to prevent load increase during forming. The machining allowances are $1.0 \mathrm{~mm}$ for the head of the rail and $0.6 \mathrm{~mm}$ for the other surfaces. A high amount of machining allowance at the head of the rail reduces the amount of metal flow through the a)

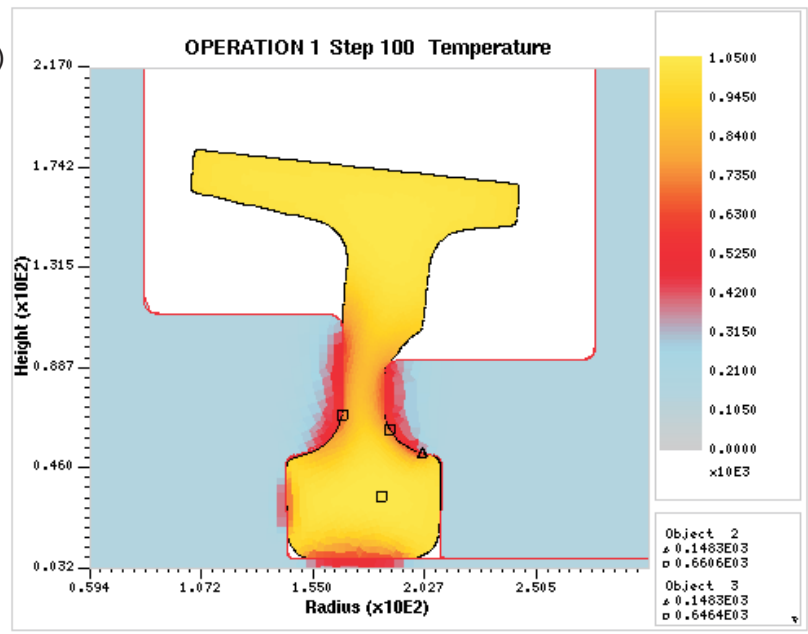

b)

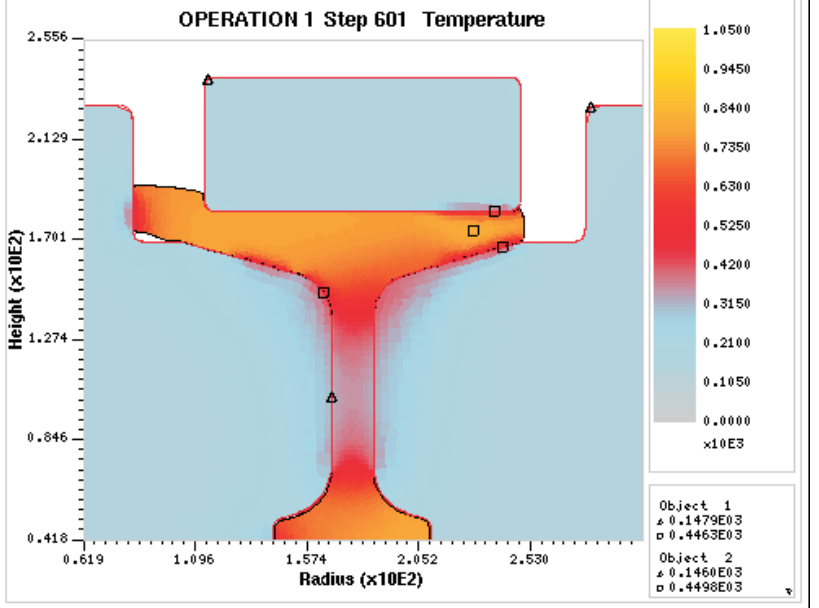

Fig. 7: Simulated results of modified process of Fig. 5: a) the end of 1 st stage, b) the end of the 5th stage

web to a relatively short rib, but the high amount of metal flow in the 3 stage process makes it possible to form the full shape of the rib. 


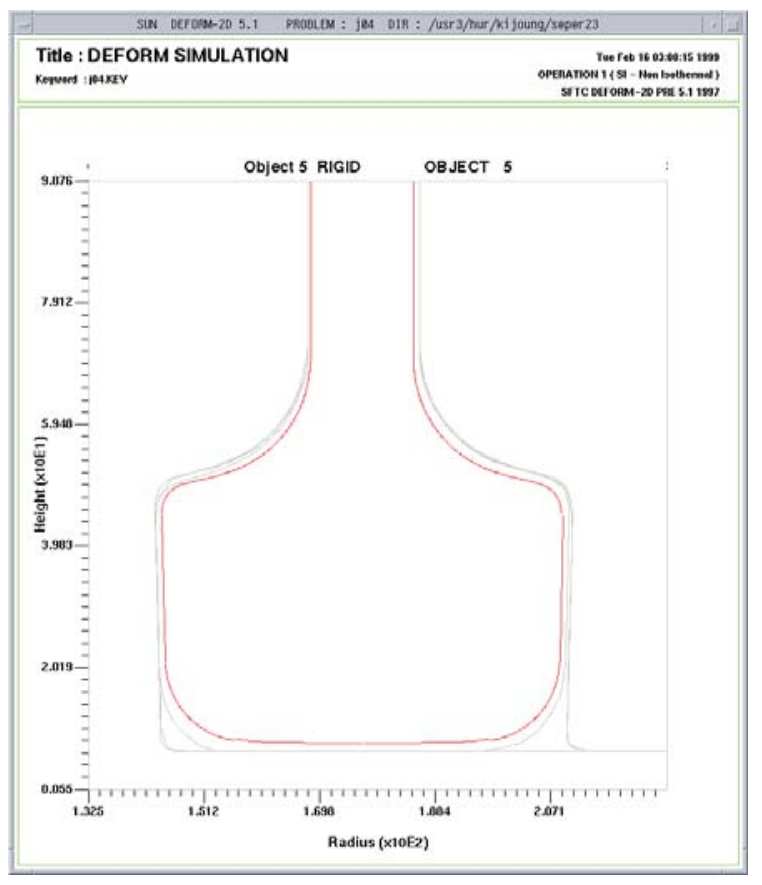

Fig. 8: Comparisons of the final forged product and the desired shape

a)

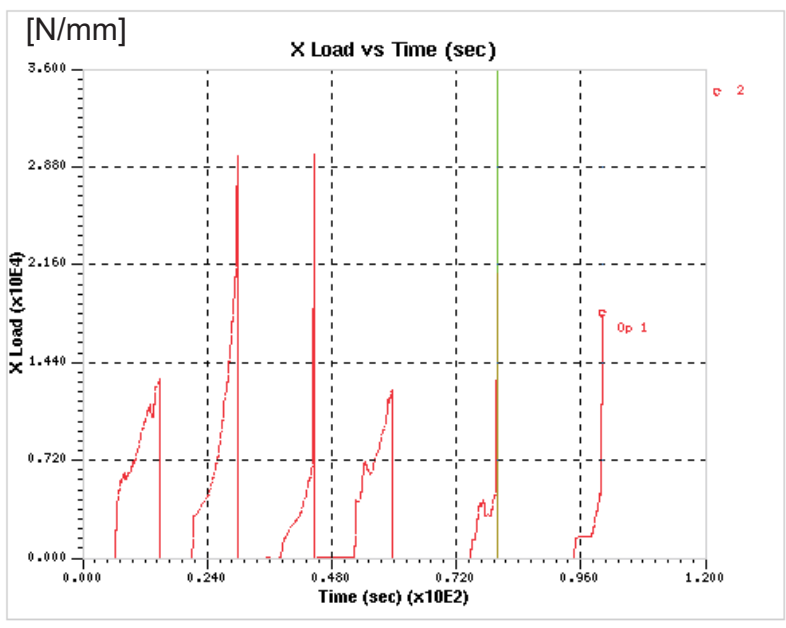

b)

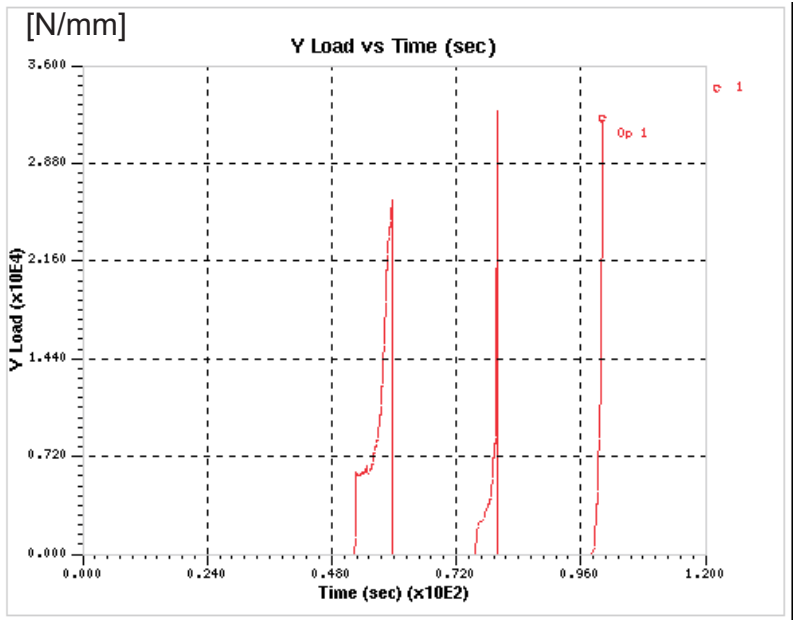

Fig. 9: Impressed load per unit length of the side and top die: a) side die, b) top die
Fig. 8 compares the final and the forged shape of the rail. The final forged shape has a sufficient machining allowance. Fig. 9 shows that the maximum forging load per unit length impressed to the right die at each stage was about $30 \mathrm{kN} / \mathrm{mm}$. As shown in the figure, the first stage (Fig. 5a and Fig. 7a), which forms the rail head, does not have the rapid increase in load that appeared in the process of Fig. 5. However, the load increase of the second and third stages shows an increase similar to that of the first stage. Though the amount of deformation in the subsequent stages decreased, the load increased rapidly because of the increased contacting area between the material and the dies, and the cooling of the material. The load per unit length impressed to the upper die was similar to that impressed to the right die (Fig. 9b). Therefore, the required press load is $30 \mathrm{kN} / \mathrm{mm} \times 720 \mathrm{~mm}=21,600 \mathrm{kN}$. If we put $2,940 \mathrm{kN}$ as the load tolerance of the press, then the press load will be $24,540 \mathrm{kN}$.

\section{Experiment}

\subsection{Testing Facility and Conditions}

On the basis of the simulation results $70 \%$ by size of the actual dies and the insert was made of $\mathrm{Al}$ 5052. Fig. 10 shows the dies and the facilities set up on the press.

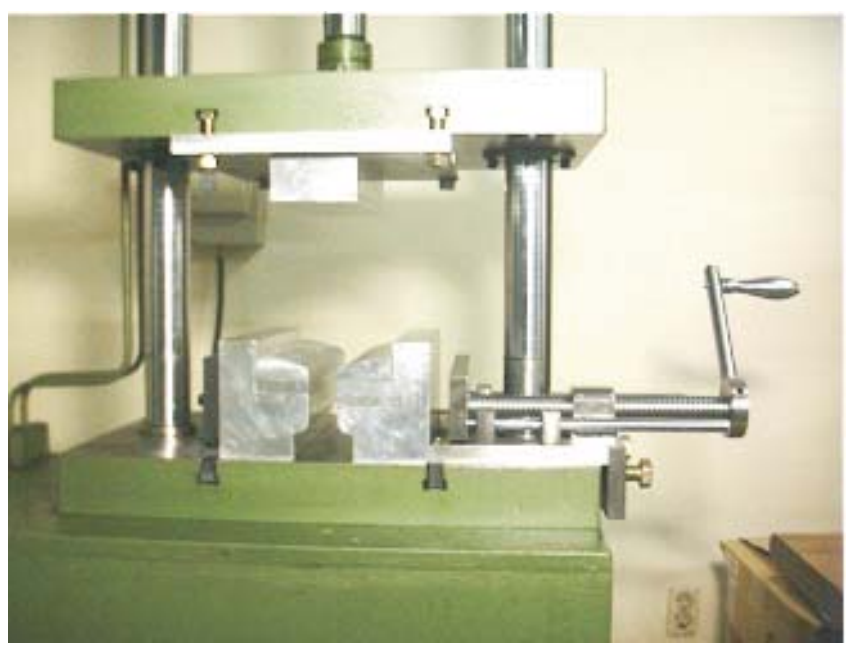

Fig. 10: Experimental set up

The rail shape specimens were made with plasticine simulation material stacked to the flow direction with $3 \mathrm{~mm}$ thick black and white plates as shown in Fig. 11a. The lubricant between the specimen and the dies was soapy water. The actual process condition was obtained with a plain strain condition by closing the opposite side of the dies to prevent material flow.

\subsection{Results}

The experiment was carried out on the basis of the simulation. Fig. 11a shows the flow of plasticine when the first stage finished. The experimental results correspond to the DEFORM $^{\mathrm{TM}}-2 \mathrm{D}$ simulation of the material flow shown in Fig. $11 b$.

Fig. 12 displays the final forged shape of the two specimens. As the process proceeds, material flows to the fixed dies, and simultaneously to the rib then nearly perpendicu- 
a)

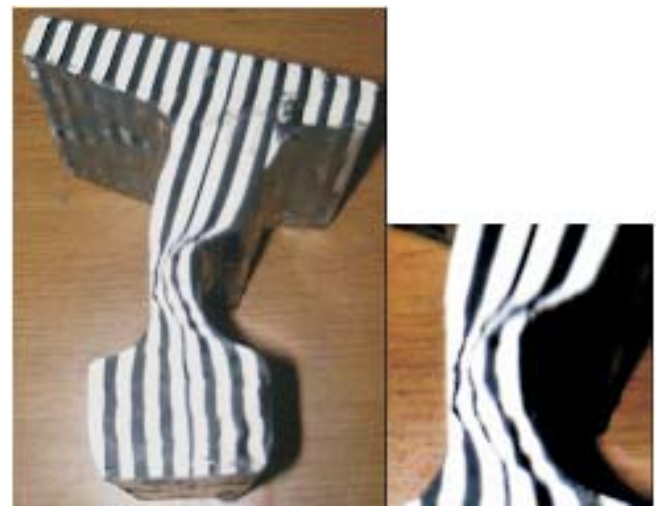

b)

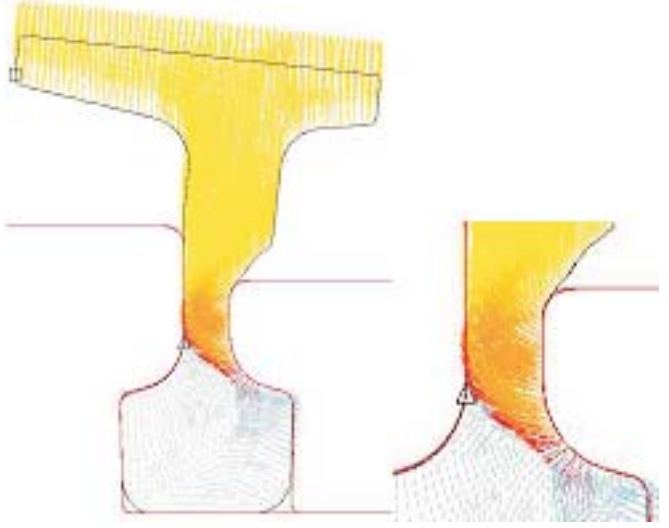

Fig. 11: Comparisons of the experimental result and the FEM simulation after the first process: a) result of the experiment, b) result of the simulation

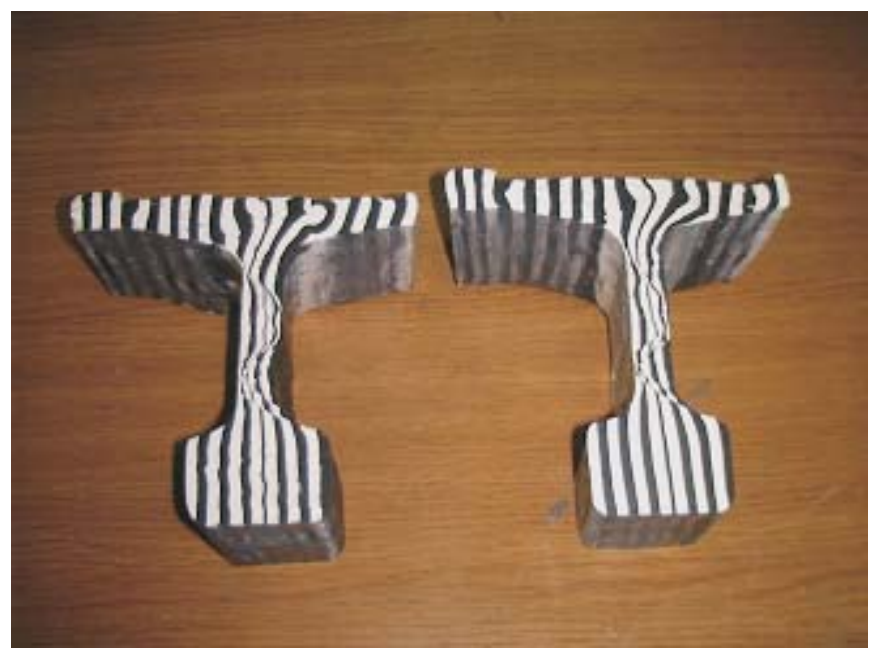

Fig. 12: Experimental result after final stage

larly and finally to the long rib. During forming with an upper die, the long rib shows a reduction in thickness because material flow occurs to the short rib. The result corresponds to the simulation result for material flow. Therefore, the process design in the present study seems to be applicable to real production.

\section{Conclusions}

1) Folding behavior and friction due to stress concentration reduced with increased fillet angle between the dies and the insert. In order to prevent folding at the cross point between the rib and the web, the beginning point of the taper to cause metal flow has to be close to the short rib.

2) In order to reduce the capacity of the press, the rail head area has to have a machining allowance, and the forming has to be finished at the first stage.

3) The experimental result corresponded to the simulated result. Therefore, the process design is applicable to actual production.

\section{References}

[1] Rodrigues, J. M. C., Martins, P. A. F.: Finite Element Modeling of the Initial Stages of a Hot Forging Cycle. Finite Element in Analysis and Design, Vol. 38, 2002, p. 295-305.

[2] Fujikawa, S.: Application of CAE for Hot Forging of Automotive Components. J. of Materials Processing Technology, Vol. 98, 2000, p. 176-181.

[3] Guo, Y. M., Nakanishi, K.: A Hot Forging Simulation by the Volumetrically Elastic and Deviatorically Rigid-Plastic Finite Element Method. J. of Materials Processing Technology, Vol. 89, 1999, p. 111-116.

[4] Ward, M. J., Miller, B. C.: Simulation of a Multi-Stage Railway Wheel and Firming Process. J. of Materials Processing Technology, Vol. 80-81, 1998, p. 206-212.

[5] Qingbin, L., Zengxiang, F.: Coupled Thermo-Mechanical Analysis of the High-Speed Hot-Forging Process. J. of Materials Processing Technology, Vol. 69, 1997, p. 190-197.

[6] Doege, E., Bohnsack, R.: Closed Die Technologies for Hot Forging. J. of Materials Processing Technology, Vol. 98, 2000, p. $165-170$.

[7] Choi, J. C., Kim, B. M., Kim, S. W.: Computer-Aided Design of Blockers for Rib-Web Type Forgings. J. of Materials Processing Technology, Vol. 54, 1995, p. 314-321.

Prof. Dr. Haeyong Cho

phone: +820432612464

fax: +820432632448

e-mail: hycho@cbucc.chungbuk.ac.kr

Byungki Oh, Ph.D.

Department. of Mechanical Engineering Chungbuk National University

Chungbuk, 361-763, Korea

Dr.Changyong Jo

High Temperature Group

Korea Institute of Machinery \& Materials

Gyungnam, 641-010, Korea

Ing. Kijoung Lee

LG Industrial Systems Co.

Chungbuk, 361-720, Korea 